\title{
Morbidities in Neonates Delivered Electively at Early Term
}

\author{
Abdul Razak ${ }^{1}$ Karthik N. Nagesh ${ }^{1,3}$ - Gayathri Karthik ${ }^{2}$. \\ Mrinal S. Pillai ${ }^{1} \cdot$ Pankaj Kumar Mohanty ${ }^{1}$
}

Received: 10 June 2015/ Accepted: 1 July 2015/Published online: 21 July 2015

(C) Federation of Obstetric \& Gynecological Societies of India 2015

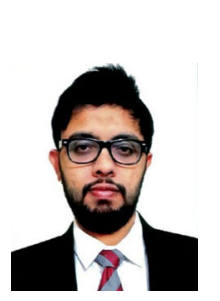

\begin{abstract}
About the Author
Dr. Abdul Razak is a neonatologist working at Manipal Hospital, Bangalore. Dr Abdul Razak is a member of "Royal college of Paediatrics and Child health" and holds the prestigious MRCPCH (UK) degree. After completing his graduation (MBBS) from JSS medical college, he pursued the Master degree in Pediatrics from Bangalore Medical College, Bangalore, RGUHS University. He underwent a structured neonatal intensive care fellowship program under Indian academy of pediatrics. He has secured various gold medals and prizes throughout his academic endeavors. He has also been awarded for being a university/state topper during his graduation at RGUHS University. Currently, he is working with the neonatal team at Manipal hospital led by the Senior Professor and Head of Department, Dr. Karthik Nagesh N. Under his guidance, the neonatal team comprising fellows and specialists has presented various papers and published many articles.
\end{abstract}

\begin{abstract}
Objective To study the incidence of elective cesarean deliveries at term and to correlate their neonatal outcomes at different gestational ages $\left(37^{0 / 7}-40^{6 / 7}\right)$.

Methods Outcomes including the rate of NICU admissions, usage of ventilator/CPAP, and other morbidities
\end{abstract}

Abdul Razak is a Neonatologist; Karthik N. Nagesh is a HOD and Chairman of Neonatology.

Karthik N. Nagesh

drkarthiknagesh@gmail.com

1 Department of Neonatology, Manipal Hospital, Bangalore, India

2 Department of Obstetrics and Gynaecology, Manipal Hospital, Bangalore, India

3 Manipal Group of Hospitals, Bangalore, India were analysed and compared with the gestational age during the study period from January 2012 to April 2013. Results The incidences of elective deliveries at 37, 38, 39 , and 40 weeks of gestation were 10.6, 29.7, 28, and $31.5 \%$, respectively. NICU admissions-RR 3.94 (95\% CI 1.92-8.09), respiratory distress-RR 5.255 (95\% CI 1.9-14.4), ventilatory usage, and hospitalization stay $(P$ value $<0.05)$ were higher in neonates born at $37^{0 / 7-6 / 7}$ versus $39^{0 / 7-6 / 7}$ weeks (least morbidity group).

Conclusion Despite recommendations, more than onethird of term babies are delivered electively at $<39$ weeks. The fivefold augmented respiratory morbidity and fourfold increased NICU admissions in early term neonates, and the least morbidity in neonates delivered at 39 weeks emphasize the importance of restricting the non-emergent/elective deliveries to 39 weeks of gestation.

Keywords Early term - Elective deliveries - LSCS . Morbidities · Neonate 


\section{Abbreviations \\ CPAP Continued positive airway pressure \\ GA Gestational age \\ LSCS Lower segment cesarean section \\ RDS Respiratory distress syndrome \\ TTNB Transient tachypnea of newborn}

\section{Introduction}

Deliveries conducted at term gestation are thought to be safe for neonatal outcome; however, evidence suggests that elective deliveries performed between 37 and 39 completed weeks of gestation are associated with significantly higher incidence of neonatal complications like RDS, TTNB, PPHN, and increased ventilation and hospitalization [1-3]. Due to the aforementioned complications, the American College of Obstetricians and Gynecologists states that elective deliveries should not be performed before 39 weeks of gestation $[4,5]$.

Fifty percentage of induction in Asian health care facilities are elective, and in India, the percentage of elective deliveries by induction is $32.1 \%$ [6]. One-third of elective inductions in Asian health care facilities occur at gestation less than 39 weeks [6]. In India, cesarean section rates were $7.1 \%$ in the year 1998, and there is a change of $16.7 \%$ in the annual rates [7]. The rates again vary with the level of care with rate reaching up to $50 \%$ in a tertiary care facility $[8,9]$.

Due to constraints of data, it is assumed that at least $30-40 \%$ of cesarean sections are elective in India [10]. In India, due to various reasons like physician and patient factors, the common practice has not changed. Apart from this, giving birth in an auspicious day is driving the women to go for a cesarean section [11]. The study is to understand the increased incidence of neonatal morbidities, a deviation in practice from guidelines of ACOG, and also to determine the effect of the same in Indian scenario.

\section{Materials and Methods}

This study was conducted in Level 3B NICU in India during January 2012 to April 2013. Gestational age was calculated from the 1st trimester USG. Newborns born by elective cesarean at term $\left(37^{0 / 7}-40^{6 / 7}\right)$ GA were included in the study. Strict admission criteria were followed as per NICU policy. Required data were entered in Excel work sheet 2007, and a statistical analysis was done using SPSS software version 17. Significance is assessed at $5 \%$ level. Analysis of variance (ANOVA) has been used to find the

Table 1 Comparison of morbidities among term babies born by elective cesarean section

\begin{tabular}{|c|c|c|c|c|c|c|c|c|}
\hline $\begin{array}{l}\text { GA } \\
\text { (weeks) }\end{array}$ & $\begin{array}{l}\text { Elective } \\
\text { LSCS } \\
\text { (n) }\end{array}$ & $\begin{array}{l}\text { NICU } \\
\text { admission (n) }\end{array}$ & $\begin{array}{l}\text { Respiratory } \\
\text { distress (n) }\end{array}$ & $\begin{array}{l}\text { CPAP } \\
\text { (n) }\end{array}$ & $\begin{array}{l}\text { Invasive } \\
\text { ventilation (n) }\end{array}$ & $\begin{array}{l}\text { Ventilation duration } \\
\text { (days) mean (SD) }\end{array}$ & $\begin{array}{l}\text { Surfactant } \\
\text { therapy (n) }\end{array}$ & $\begin{array}{l}\text { Hospital stay (days) } \\
\text { mean (SD) }\end{array}$ \\
\hline 37 & 43 & 15 & 10 & 6 & 4 & $9 \pm 1.8$ & 4 & $8.2 \pm 1.5$ \\
\hline 38 & 120 & 14 & 5 & 4 & 1 & $4.2 \pm 1.3$ & 1 & $4.1 \pm 0.86$ \\
\hline 39 & 113 & 10 & 5 & 4 & 0 & $2 \pm 0.8$ & 0 & $3.6 \pm 0.69$ \\
\hline 40 & 127 & 17 & 6 & 4 & 0 & $4.8 \pm 1.4$ & 0 & $4.9 \pm 1.51$ \\
\hline Total & 403 & 56 & 26 & 18 & 5 & - & 5 & - \\
\hline$P$ value $^{\mathrm{a}}$ & - & 0.0005 & 0.0005 & 0.02 & 0.0009 & - & 0.0009 & - \\
\hline$P$ value $^{\mathrm{b}}$ & - & 0.5 & 1 & 1 & 1 & 0.0001 & 1 & 0.14 \\
\hline$P$ value ${ }^{c}$ & - & 0.3 & 1 & 1 & 1 & 0.0001 & 1 & 0.01 \\
\hline
\end{tabular}

Bold values indicate $p<0.05$

Comparing between neonates born at different gestational age, ${ }^{\mathrm{a}} 37 / 38 / 39$ weeks $-P$ value, ${ }^{\mathrm{b}} 38 / 39$ weeks $-P$ value, ${ }^{\mathrm{c}} 39 / 40$ weeks $-P$ value

Table 2 Risk of respiratory morbidity between neonates born at term gestation

\begin{tabular}{llll}
\hline & \multicolumn{2}{l}{ Relative risk $(95 \%$ CI) } & \\
\cline { 2 - 4 } & 37 versus 39 weeks & 38 versus 39 weeks & 40 versus 39 weeks \\
\hline Respiratory distress & $5.255(1.9-14.4)$ & $0.94(0.28-3.16)$ & $1.06(0.33-3.4)$ \\
CPAP & $3.94(1.6-13.2)$ & $0.94(0.4-3.6)$ & $0.88(0.22-3.4)$ \\
NICU admission & $3.94(1.92-8.09)$ & $1.31(0.61-2.84)$ & $1.5(0.72-3.16)$ \\
\hline
\end{tabular}

Relative risk $=1$ for 39 weeks gestation 
significance of study parameters among three or more groups of patients, and a Chi-square/Fisher Exact test has been used to find the significance of study parameters on categorical scale between two or more groups. Relative risk (RR) was calculated with $95 \%$ confidence intervals for categorical variables.

\section{Results}

During the study period, there were total 1879 deliveries, out of which 1170 cesarean deliveries occurred. Out of this, the number of elective cesarean sections was 403 . Forty percent of the elective surgeries occurred at less than 39 weeks of gestational age (Table 1). The indications for the cesarean sections were previous LSCS $(n=232)$, failed induction $(n=38)$, breech $(n=31)$, placenta previa $(n=45)$, twin gestation $(n=36)$, and oligohydraminos $(n=21)$. The maximum admissions to NICU occurred among neonates born at 37 weeks of gestational age and the minimum at 39 weeks. It was noted that respiratory distress was the major cause of NICU admissions apart from other causes such as hypoglycemia, feed intolerance, sepsis, neonatal hyperbilirubinemia, and perinatal asphyxia. The numbers for nonrespiratory causes for NICU admission were fewer to compare between the groups. The incidence of respiratory distress was highest in the early-term gestational age at 37 weeks $(23.2 \%)$. Transient tachypnea of newborn (TTNB) requiring CPAP support was the most common cause $(69.2 \%)$ of respiratory support. The average duration [mean (SD)] of ventilation in days was highest at 37 weeks of gestational age [9 (1.8) days] and least at 39 weeks of gestational age [2 (0.8) days]. The average duration of hospital stay also followed a similar pattern with a maximum at 37 weeks of gestational age [8.2 (1.5) days], then decreased to a nadir of $3.6(0.19)$ days at 39 weeks of gestational age, and again showed an increasing trend of 4.9 (1.5) days at 40 weeks of gestational age.

\section{Discussion}

Our study shows that a large percentage of elective cesarean sections occurred at early term gestation. Morbidities are highest at 37 weeks of gestational age, reach a nadir at 39 weeks of gestation, and show an increasing trend at 40 weeks of gestation. Morbidities when plotted assume a U-shaped curve, reflecting poor outcomes at both the extremes ( 37 and 40 weeks). Studies from various centers in Europe and the US have shown a similar distribution of neonatal morbidities [1-3].

Parikh et al. found that the respiratory morbidity was higher at 37 weeks than at 39 weeks GA regardless of the route of delivery. NICU admissions and respiratory morbidity were lowest at or beyond 39 weeks GA compared to those at the early-term period [12]. Sengupta et al. showed that, compared with term infants, early-term neonates had significantly higher risks for the following: hypoglycemia (OR 1.92), NICU admission (OR 1.64), need for respiratory support (OR 1.93), requirement for intravenous fluids/ antibiotics (OR 1.68), and mechanical ventilation/intubation (OR 4.57) [13]. Hillary KB et al. showed that, compared with infants born full term, infants born late preterm and early term were at increased risk for neonatal intensive care unit triage/admission and respiratory morbidity [14].

In our study, the admission to NICU and RDS was increased by five and fourfold, respectively, if the infant was born at 37 weeks compared to 39 weeks GA (Table 2). Surprisingly, the incidences of respiratory distress and NICU admissions were comparable between 37,39 , and 40 weeks; however, the durations of ventilation and hospitalization were significantly higher. The durations of ventilation and hospital stay were higher in babies born at 40 weeks because of the primary respiratory disease (MAS/Pneumonia), different from babies born at 37/38 weeks (RDS/TTNB). For this reason, we would recommend that the ideal time line to conduct delivery is at 39 weeks which contradicts from the original recommendation (39-40 weeks).

The major limitations of our study were that it is a single-center study, and the effect of mode of delivery on neonatal morbidities was not determined by having a comparison group with neonates born by vaginal delivery. Our study emphasizes on the time line of elective deliveries which is conducted early despite the evidence stating performing at 39 weeks GA.

Financial Disclosure The authors have indicated that they have no financial relationships relevant to this article to disclose.

Funding None.

Complaince with Ethical Requirements and Conflict of Interest This study did not require ethical clearance by the Institutional Ethics Committee as it was an observational analytical study. The authors have no conflicts of interest relevant to this article to disclose.

\section{References}

1. Oshiro BT, Henry E, Wilson J, et al. Decreasing elective deliveries before 39 weeks of gestation in an integrated health care system. Obstet Gynecol. 2009;113:80411.

2. Shapiro-Mendoza CK, Tomashek KM, Kotelchuck M, et al. Effect of latepreterm birth and maternal medical conditions on newborn morbidity risk. Pediatr. 2008;121:e223-32.

3. Tita ATN, Landon MB, Spong CY, et al. Timing of elective repeat cesarean delivery at term and neonatal outcome. N Engl J Med. 2009;360:111-20. 
4. American College of Obstetricians and Gynecologists. Induction of labor. ACOG practice bulletin 10. Washington, DC: ACOG; 1999.

5. American College of Obstetricians and Gynecologists. ACOG practice bulletin no. 97: fetal lung maturity. Obstet Gynecol. 2008;112:717-26.

6. Vogel JP, Souza JP, Gulmezoglu AM. Patterns and outcomes of induction of labour in Africa and Asia: a secondary analysis of the WHO global survey on maternal and neonatal health. PLoS One. 2013;8(6):1-11.

7. Cynthia SK, Sara HA. Levels and trends in cesarean birth in the developing world. Stud Fam Plann. 2006;37(1):41-8.

8. Pahari K, Ghosh A. Study of pregnancy outcome over a period of five years in a postgraduate Institute of West Bengal. J Indian Med Assoc. 1997;95(6):172-4.

9. Sreevidya S, Sathiyasekaran BW. High cesarean rates in Madras (India): a population-based cross sectional study. Brit J Obstet Gynaecol. 2003;110(2):106-11.
10. Kairun N. Indications of cesarean section — study of 100 cases in Mymensingh Medical College Hospital. J Shaheed Suhrawardy Med Coll. 2009;1(1):6-10.

11. Mishra US, Ramanathan M. Delivery-related complications and determinants of cesarean section rates in India. Health Policy Plan. 2002;17(1):90-8.

12. Parikh LI, Reddy UM, Mannisto T, et al. Neonatal outcomes in early term birth. Am J Obstet Gynecol. 2014;211:265.e1-11.

13. Sengupta S, Carrion V, Shelton J, et al. Adverse neonatal outcomes associated with early-term birth. JAMA Pediatr. 2014;168(1):53.

14. Hilary KB, Kathy NS, Jennifer M, et al. Neonatal morbidity associated with late preterm and early term birth: the roles of gestational age and biological determinants of preterm birth. Int $\mathbf{J}$ Epidemiol 2014;43(3):802-14. 